STRUCTURAL BIOLOGY COMMUNICATIONS

ISSN 2053-230X

₹ Guest Editor for this special issue.

Keywords: special issues; carbohydrates; glycoproteins; protein-carbohydrate complexes

Acta Crystallographica Section F STRUCTURAL BIOLOGY COMMUNICATIONS

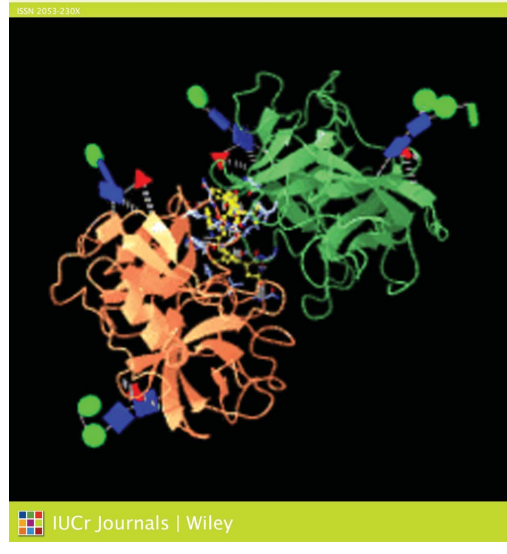

(C) 2018 International Union of Crystallography

\section{Carbohydrate structure hits the groove}

\author{
Jon Agirre ${ }^{\mathrm{a} *} \ddagger$ and Mark J. van Raaij ${ }^{\mathrm{b} *}$
}

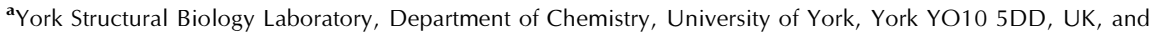

${ }^{\mathbf{b}}$ Department of Molecular Structure, Centro Nacional de Biotecnologia, Consejo Superior de Investigaciones Cientificas, E-28049 Madrid, Spain. *Correspondence e-mail: jon.agirre@york.ac.uk, mjvanraaij@cnb.csic.es

We are pleased to introduce the first Acta Cryst. F special issue on Crystallography of glycoproteins and protein-carbohydrate complexes. We hope to present not only structural information but also cutting-edge methodology that will boost our understanding of the three-dimensional intricacies pertaining to the chemistry of carbohydrates.

How are polysaccharides synthesized, cleaved, modified or linked together? Basic questions, whose answers will help us meet the biotechnological challenges of the future, as humanity grapples with the consequences of an industrial revolution powered by unsustainable combustion of fossil fuels. Saccharides, ubiquitous in the biosphere, can be industrially turned into green fuel provided that the enzymatic processes governing the conversion can be understood, optimized and harnessed. Carbohydrates, with their regioand stereochemical complexity, make highly demanding substrates in structural terms and in virtually any other term. In protein glycosylation, their stereoselectivity can play a vital role in recognition processes, but it can also jeopardize intramolecular stability when glycan composition does not dovetail effectively with its protein surroundings: it is a case of structure determines function, with a heavy emphasis on the structure. To highlight these points, in this special issue we present topical reviews on structural and mechanistic aspects of protein $O$-fucosylation (Lira-Navarrete \& Hurtado-Guerrero, 2018), and on using NMR spectroscopy and X-ray crystallography to elucidate protein-glycan interactions in a complementary way (Blaum et al., 2018).

Anecdotally, $10 \%$ of the structures deposited annually in the wwPDB contain carbohydrates, with more than half of that percentage showing some form of glycosylation (Agirre, 2017). Our knowledge of the structure of carbohydrates, but especially of their function as post- and co-translational modifications, is now increasing exponentially. It has perhaps lagged behind that of protein and nucleic acids in recent decades, but as a community we now have the mature biochemical arsenal required to produce functional glycosylated proteins, in quantities and with the quality suitable for structural analysis microheterogeneity permitting - by the three major techniques of X-ray crystallography, cryo-EM and NMR spectroscopy. We still have some work to do on methodology to support these: from the formation of crystal complexes to the way we build, refine, deposit and represent our saccharides, the whole process is open to innovation.

On the programmatic side, a number of developments have been gathering steam, spearheaded by Lütteke's critical analysis of carbohydrate structures in the PDB (Lütteke et al., 2004). Lütteke himself is trying to give PDB data a new lease of life, with new work presented here in collaboration with Robbie P. Joosten (van Beusekom et al., 2018). Their PDB-REDO project gives crystallography a second chance to explain electron densities through automation, and with so many incorrect structures there is plenty of room for improvement.

Recently in 2018, in addition to the developments presented in this issue and those recently introduced in Agirre et al. (2017), we have seen the introduction of a new semiautomated modelling tool for protein N-glycosylation in Coot (Emsley \& Crispin, 2018) and the three-dimensional visualization of glycans, based on the standard Symbol Nomenclature for Glycans (SNFG), in LiteMol (Sehnal et al., 2017), which is readily available for every carbohydrate-containing structure at PDBe (https://www.ebi.ac.uk/ pdbe/litemol). Also a plethora of new developments can be found at glycosciences.de, the web portal stalwart that has supported carbohydrate structure determination for more than a decade. An example of how this portal serves the community can be found in the review of the conformations of the type- 1 lacto- $N$-biose I unit in protein complex structures published in this issue (Fushinobu, 2018). 
In the remainder of the special issue we publish the structures of the highly glycosylated human leukocyte elastase in complex with an inhibitor (Hochscherf et al., 2018), of several enzymes that act on carbohydrates (Moroz et al., 2018; Urresti et al., 2018; Wu \& Davies, 2018) and of a transcriptional regulator bound to a glycan effector (Mahounga et al., 2018).

It looks like carbohydrate structural biologists - computational methods developers and experimentalists alike - are hitting a groove on carbohydrate structure determination. Let us hope we are in for a very Long Player! Accompanying the 'music' we intend to publish more articles on this topic in the future.

Following in the footsteps of the successful special issues on Structural Genomics (Weiss \& Einspahr, 2010, 2011) and Molecular Parasitology (Hunter \& Weiss, 2015), this issue highlights carbohydrate structural biology, and together with further special issues on other topics, aims to showcase the expanding scope of Acta Cryst. F.

\section{References}

Agirre, J. (2017). Acta Cryst. D73, 171-186.

Agirre, J., Davies, G. J., Wilson, K. S. \& Cowtan, K. D. (2017). Curr. Opin. Struct. Biol. 44, 39-47.
Beusekom, B. van, Lütteke, T. \& Joosten, R. P. (2018). Acta Cryst. F74, 463-472.

Blaum, B., Nue, U., Peters, T. \& Stehle, T. (2018). Acta Cryst. F74, 452-462.

Emsley, P. \& Crispin, M. (2018). Acta Cryst. D74, 256-263.

Fushinobu, S. (2018). Acta Cryst. F74, 473-479.

Hochscherf, J., Pietsch, M., Tieu, W., Kuan, K., Abell, A. D., Gutschow, M. \& Karsten Niefind, K. (2018). Acta Cryst. F74, 480489.

Hunter, W. N. \& Weiss, M. S. (2015). Acta Cryst. F71, 483484.

Lira-Navarrete, E. \& Hurtado-Guerrero, R. (2018). Acta Cryst. F74, 443-450.

Lütteke, T., Frank, M. \& von der Lieth, C. W. (2004). Carbohydr. Res. 339, 1015-1020.

Mahounga, D. M., Sun, H. \& Jiang, Y. (2018). Acta Cryst. F74, 506511.

Moroz, O. V., Sobala, L., Blagova, E., Coyle, T., Wei, P., Morkeberg Krogh, K. B. R., Stubbs, K. A., Wilson, K. S. \& Davies, G. J. (2018). Acta Cryst. F74, 490-495.

Sehnal, D., Deshpande, M., Vařeková, R. S., Mir, S., Berka, K., Midlik, A., Pravda, L., Velankar, S. \& Koča, J. (2017). Nat. Methods, 14, 1121-1122.

Urresti, S., Cartmell, A., Liu, F., Walton, P. H. \& Davies, G. J. (2018). Acta Cryst. F74, 496-505.

Weiss, M. S. \& Einspahr, H. (2010). Acta Cryst. F66, 1406.

Weiss, M. S. \& Einspahr, H. (2011). Acta Cryst. F67, 1159.

Wu, L. \& Davies, G. J. (2018). Acta Cryst. F74, 512-523. 